\title{
Presence of microorganisms in commonly used baby cosmetics, available in Dhaka City
}

\author{
Farahnaaz Feroz* and Kamal Kanta Das
}

Department of Microbiology, Stamford University Bangladesh, 51, Siddeswari Road, Dhaka-1217, Bangladesh

Received 14 April 2019/Accepted 21 May 2019

\begin{abstract}
Cosmetics especially baby products should be safe as children are immunocompromised which means their immune system is not developed enough to combat infections caused by the presence of any pathogenic bacteria. Different factors like chemical composition of cosmetics, handling and storage conditions can influence the chance of contamination of cosmetic products. This study aimed to evaluate the microbiological quality of different commercially available baby cosmetics such as body lotion, body wash or soap, baby shampoo, baby oil of different popular brands sold in Dhaka city. In the current investigation four different brands of cosmetics were subjected to bacteriological and mycological screening. Total viable bacteria and fungal load in all the samples of Brand 1 was in average of $10^{5} \mathrm{cfu} / \mathrm{g}$ which exceeded the acceptable limit. The samples were found to contain pathogenic bacteria as well, especially Klebsiella spp. The findings indicate that the quality Brand 1 products were not satifactory and might cause harm to children and other consumers. Microbial load of other brands fell within the acceptable limit which indicate their good quality. The incidence of microorganisms in Brand 1 might be due to contamination during the production process or storage under unhygienic condition. Therefore in order to avoid infections in children due to microbial contamination of cosmetics items it is essential to take precautions during production process and storage in appropriate conditions and avoiding use of cosmetics products on damaged skin.
\end{abstract}

Keywords: Baby cosmetics, Microbiological analysis, Consumer safety, Microbial contamination.

\section{INTRODUCTION}

Cosmetic products are used worldwide to ensure or enhance hygiene and beauty and a variety of products are commercially available to be used by consumers (1-4). Cosmetic items are not only used by adults but also used by children after birth. Although used in washing from impurities and beautification, its' composition includes natural herbs as well as chemical substances, which could potentially cause allergic reactions among the users (3-5). Cosmetics are considered non-sterile pharmaceutical products therefore they are susceptible to microbial and fungal contamination with contaminant like Staphylococcus aureus, Pseudomonas spp. along with some Gram negative bacteria $(1,3,4)$. Although many preservatives are used during production to prevent contamination, several factors may lead to the contamination of cosmetic products such as raw material spoilage, lack of quality assessment examinations prior to release in the market, contamination during production, storage conditions and the presence of ingredients which favor microbial growth (3-5, 6-8). Warm and humid environment of Bangladesh are favourable for the growth of microorganisms $(3-5,9)$.

Skin diseases are more likely to occur in developing countries, due to overcrowded population and lack of knowledge of hygiene $(4-5,10)$. Acne, eczema and other skin related disorders can result from use of contaminated healthcare products (3-4). Several guidelines are followed to conform the quality of cosmetics used such as, British Pharmacopeia (BP), United States Pharmacopeia (USP) and European Pharmacopeia (EP) $(4,8,10,11,20)$. Therefore, it is imperative to ensure that these products and their raw materials are free from microorganisms and produced in accordance with the guidelines of Good Manufacturing Practices and Food and Drug Administration to ensure that they serve their purpose without causing harm to the skin of consumers (3-4). This is particularly important for cosmetics applied on babies as their skins are more sensitive than those of adults. The major complications arise from the fact, that unlike medication, there is a lack of proper testing method and procedure to maintain quality of cosmetics in Bangladesh (3-5). Proper testing requires frequent examination of both raw and finished products, in order to maintain the quality and consumer safety $(3,4,12)$.

It is important to have detailed knowledge of the presence and absence microorganisms used by children, especially infants, and carry out frequent microbiological profiling of cosmetics. While analysis of medication and cosmetics available in Dhaka has been well documented, the profiling of baby cosmetics, which are used daily, is limited. For this reason, the current study assessed the quality of baby cosmetics such as lotion, baby wash and shampoo, in an attempt to identify contaminants, if present. This 
would prevent unwanted skin complications and unpleasant conditions, and provide insight into the status of products used by children.

\section{MATERIALS AND METHODS}

Sample collection and preparation. Different categories baby cosmetic (body lotion, body wash or soap, baby shampoo, baby oil) of four common brands were collected from local markets, where appropriate dates of manufacturing and expiry date was checked. After that, they were brought to the laboratory immediately, and tested as soon as possible. All samples were tested to assess the bacterial and fungal load as well the presence of specific pathogenic bacteria using the standard microbiological and biochemica methods. For microbial analysis $10 \mathrm{~g}$ of samples were diluted in $90 \mathrm{ml}$ of normal saline and mixed thoroughly and serially diluted to $10^{-6}$.

Microbiological analysis. Enumeration of total viable bacteria (TVB) and total fungal count (TFC) $0.1 \mathrm{ml}$ of sample from the dilution $10^{-2}, 10^{-4}$, and $10^{-}$ ${ }^{6}$ were plated on Nutrient agar for enumerating total viable count (TVC) and on Sabouraud dextrose agar (SDA) plate for the estimation of fungal load. After inoculation, all the plates were incubated at $37^{\circ} \mathrm{C}$ for 18 to $24 \mathrm{~h}$ and at $25^{\circ} \mathrm{C}$ for 48 to $72 \mathrm{~h}$, respectively.

Enumeration of specific pathogens. From the dilution of $10^{-2}$ of each sample, $0.1 \mathrm{ml}$ of sample was spread MacConkey agar, mannitol salt agar (MSA), Pseudomonas agar and phenol red egg yolk polymyxin (MYP) agar base media for the enumeration of total coliform (Escherichia coli and Klebsiella spp.), Staphylococcus spp., Pseudomonas spp., and Bacillus spp., consecutively. After inoculation all the plates were placed for incubated at $37^{\circ} \mathrm{C}$ for $24 \mathrm{~h}$. After incubation, the growth was counted and $\mathrm{CFU}$ (colony forming unit) was measured $(3,4,10,11)$. For further confirmation and identification of bacterial isolates biochemical tests were carried out.

\section{RESULTS AND DISCUSSION}

Brand 1 cosmetics revealed counts of aerobic bacteria above the standard limit of USP and FDA whereas Klebsiella spp. was found in all samples of Brand 1 (Table 1). Pseudomonas spp. was found in some samples and the least common contaminant $E$. coli was found in only one sample which was confirmed by standard biochemical identifications (Table 2) (20). This is alarming for Brand 1 as it is a well reputed company which has already been gained the faith of the consumers. The results of Brand 2 were within the limits as stated. Staphylococcus spp. and Bacillus spp. were not found in any samples.
Similar results were observed in Brand 3 and 4 (Table 1). This is to be noted that Brand 1 has previously been reported in the newspaper due to contamination in products released into the market .

Babies have weaker immune system, therefore the presence of pathogens in lotions and body soap could easily enter into the damage their skins. In order to ensure the safety of children, baby products should be free of microorganisms. Contaminated cosmetics can be the cause of diseases such as acne, scabies, eczema and dyschromia (5). Bangladesh as a developing country, has a higher rate of skin disease due to the overpopulation and lack of knowledge of hygiene (1316). Additionally, cosmetics composition include, water, lipids, polysaccharides, alcohol, protein and amino acids, which can promote the growth of pathogenic bacteria (17-19). In order to ensure the quality of the cosmetics items as per the guidelines of Food and Drug Administration (FDA) and Good Manufacturing Practices (GMP), necessary tests must be done on both the raw and the finished products (35).

Previous studies conducted on adult cosmetics have shown microbial load of $10^{2}$ to $10^{5} \mathrm{cfu} / \mathrm{g}$ and fungal growth of $10^{3} \mathrm{cfu} / \mathrm{g}(3,4,9,17)$ as in Brand 1 products in present study Although cosmetics need not to be sterile, it should be free from pathogenic microorganisms as they are often associated with skin infections and health related problems (1). One such method could be through the modification of the preservation system used throughout the different stages of production, storage and use (1, 3-5). The water used during production should also be closely monitored, as it could serve as a major source of contamination (9).

Table 1. Presence of pathogenic microorganisms in baby cosmetics (cfu/g)

\begin{tabular}{|c|c|c|c|c|c|c|c|}
\hline Sample & \multicolumn{7}{|c|}{ Microbial colony counts (cfu/g) } \\
\hline \multicolumn{8}{|l|}{ Brand 1} \\
\hline Oil & $2.3 \times 10^{5}$ & $1.3 \times 10^{5}$ & 0 & $7.6 \times 10^{2}$ & 0 & $3.6 \times 10^{3}$ & 0 \\
\hline Body wash & $2.4 \times 10^{5}$ & $1.4 \times 10^{4}$ & $1.0 \times 10^{2}$ & $6.3 \times 10^{2}$ & 0 & 0 & 0 \\
\hline Shampoo & $3.2 \times 10^{5}$ & $1.1 \times 10^{5}$ & 0 & $1.8 \times 10^{3}$ & 0 & $7.8 \times 10^{3}$ & 0 \\
\hline \multicolumn{8}{|l|}{ Brand 2} \\
\hline Lotion & $1.8 \times 10^{3}$ & $1.4 \times 10^{2}$ & 0 & 0 & 0 & 0 & 0 \\
\hline Soap bar & $2.3 \times 10^{2}$ & $1.1 \times 10^{1}$ & 0 & 0 & 0 & 0 & 0 \\
\hline Shampoo & $2.5 \times 10^{3}$ & $1.4 \times 10^{2}$ & 0 & 0 & 0 & 0 & 0 \\
\hline \multicolumn{8}{|l|}{ Brand 4} \\
\hline Lotion & $2.1 \times 10^{3}$ & $1.1 \times 10^{2}$ & 0 & 0 & 0 & 0 & 0 \\
\hline Body wash & $7.8 \times 10^{2}$ & 0 & 0 & 0 & 0 & 0 & 0 \\
\hline Shampoo & $2.5 \times 10^{3}$ & $1.8 \times 10^{2}$ & 0 & 0 & 0 & 0 & 0 \\
\hline
\end{tabular}

Microbial limit. USP or FDA limit of aerobic bacteria $<10^{3} \mathrm{cfu} / \mathrm{g}$ for products of non-eye area, eye area 500 colony forming units (cfu)/g 
Tables 2. Confirmative biochemical tests for the isolates

\begin{tabular}{|c|c|c|c|c|c|c|c|c|c|c|}
\hline \multirow{2}{*}{ Organism isolated } & \multicolumn{3}{|c|}{ TSI } & \multirow{2}{*}{$\stackrel{\infty}{=}$} & \multirow{2}{*}{$\begin{array}{l}\frac{0}{0} \\
\frac{\sigma}{\Xi}\end{array}$} & \multirow{2}{*}{$\stackrel{\Omega}{\xi}$} & \multirow{2}{*}{$\hat{s}$} & \multirow{2}{*}{ 节 } & \multirow{2}{*}{ 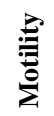 } & \multirow{2}{*}{ 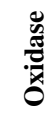 } \\
\hline & slant & butt & gas & & & & & & & \\
\hline E. coli & $\mathrm{Y}$ & $\mathrm{Y}$ & + & - & + & + & - & - & + & \\
\hline Klebsiella spp. & $\mathrm{Y}$ & $\mathrm{Y}$ & - & - & - & - & - & - & - & + \\
\hline Pseudomonas spp. & $\mathrm{R}$ & $\mathrm{R}$ & - & - & - & - & - & + & - & - \\
\hline
\end{tabular}

TSI $=$ Triple Sugar Iron Test Y = Yellow (Acid) $; \mathrm{R}=$ Red (Alkaline); MR = Methyl Red $;$ VP = Voges-Proskauer

\section{CONCLUSION}

Although current study found products of Brands 2, 3 and 4 to be within the limits set by the regulatory bodies, those of Brand 1 was found to be exceeding it. This is cause for alarm as this brand is commonly used and easily available in the markets of Bangladesh. Baby's immune systems are more susceptible to the harmful effects of bacteria and chemicals. So, popular brands need to increase their effort to ensure that both their raw products and finished goods are free from microorganisms. This is imperative in ensuring that the consumer is safe from their products.

\section{REFERENCES}

1. Eldesoukey RMM, Alqhtani BS, Alqhtani AS, Alqhtani AH and Malqhtani AM. 2016. Comparitive microbiological study between traditional and modern cosmetics in Saudi Arabia. Enz. Engineer. 5:2.

2. Elmorsy TH and Hafez EA. 2016. Microbial Contamination of Some Cosmetic Preparations in Egypt. Int. J. Agr. Techn. 12:471-481.

3. Akon T, Das KK, Nitu LN and Noor R. 2015. Demonstration of in vitro anti-bacterial activity of the popular cosmetics items used by the Dhaka locality. Asian Pac. J. Trop. Dis. 5 (suppl. 1): S121 - S126.

4. Das KK, Fatema KK, Nur IT, and Noor R. 2013. Prevalence of Microorganisms in commonly used cosmetics samples in Dhaka Metropolis. J. Pharm. Sci. Inno. 2:7-9

5. Noor R, Zerin N, Das KK and Nitu LN. 2015. Safe Usage of Cosmetics in Bangladesh: a quality perspective based on microbiological attributes. J. Biol. Res. (Thessalon). 22:10.
6. NakiSiviri N, Ozar AY, Ozalp M, Atakan N and Polat M. 2006 Decontamination of cosmetic products and raw materials by gamma irradiation. FABAD J. Pharm. Sci. 31:198-209.

7. Summera R, Iqbal S and Shahina SJ. 2015. Bacteriological profile and preservative capacity of commercial creams and lotions. UK. J. Pharm. Biosci. 3:41-45.

8. Huda JM. 2011. Bacterial and Fungal Contamination in Three Brands of Cosmetic Marketed in Iraq. Iraqi J. Pharm. Sci. 20:38-42.

9. Hugbo PG, Onyekweli AO and Igwe I. 2003. Microbial contamination and preservative capacity of some brands of cosmetic creams. Trop. J. Pharm. Res. 2:229-234.

10. Khanom S, Das KK, Banik S and Noor R. 2013. Microbiological analysis of liquid oral drugs available in Bangladesh. Int. J. Pharm. Pharm. Sci. 5:479-482

11. Rana J, Sultana T, Das KK and Noor R. 2014. Microbiological analysis of topical available in Bangladesh. Int. J. Pharm. Pharm. Sci. 6:330-332.

12. Jimenez L, Ignar R, Smalls S, Grech P, Hamilton J, Bosko and English D. 1999. Molecular detection of bacterial indicators in cosmetics/ pharmaceuticals and raw materials. J. Ind. Micro. Biotec. 22:93-95.

13. Prüss-Üstün A and Corvalán C. 2006. Preventing disease through healthy environ- ments: Towards an estimate of the environmental burden of disease. Geneva: WHO Press.

14. Cundell AM. 2005a. Environmental monitoring in non-sterile product manufacturing. In: Moldenhauser J, editor. Environment monitoring. Davis Horwood/PDA. 217-30.

15. Cundell AM. 2005b. Managing the microbiological quality of pharmaceutical excipients. PDA J. Pharma. Sci. Technol. 59:381-95.

16. Denyer SP, Hodges NA, Gorman SP, Hugo W and Russell A. 2004 Pharmaceutical microbiology. $7^{\text {th }}$ ed. London: Blackwell Science.

17. Techaoei S. 2017. Bacterial and Fungal Contamination of Personal Care Product in Northern Thailand. RJ. RMUTT. 16:1-2.

18. Siegert W. 2012. Microbiological quality management for the production of cosmetics and detergents. S.O.F.W. J. 138(11-2012):1-9.

19. Herrera AG. 2004. Microbiological analysis of cosmetics. Methods Mol. Biol. 268:293-295.

20. United States Pharmacopeia (USP). 2003. Microbiological examination of non-sterile products: tests for specified microorganisms. Pharm. Forum 29:1722-33. 